Жукова Марина Александровна

д-р экон. наук, ФГБОУ ВО «Государственный университет управления», г. Москва

e-mail: zhukova_marina@inbox.ru

\section{Zhukova Marina}

Doctor of Economic Sciences, State University of Management, Moscow e-mail: zhukova_marina@inbox.ru

\section{УПРАВЛЕНИЕ МОТИВАЦИЕЙ ПОТРЕБИТЕЛЯ ТУРИСТСКИХ УСЛУГ}

\begin{abstract}
Аннотация. Рассмотрены мотивы, которыми руководствуются путешественники при выборе туристского продукта. Мотивы туристов разделены на три вида в зависимости от степени взаимообусловленности первичных и вторичных мотивов. Выявлены тенденции, оказывающче значительное влияние на формирование мотиваций потребителей туристских и гостиничных услуг. На основе анализа разнообразных теоретических концепций туристской мотивации (аналитических, иерархических и комплексных) предложено сгруппировать мотивации туристов в следующие группы: физические мотиваичи на отдых; культурные и природно-климатические; социальные; мотивации изменения вида деятельности; статуса и престижа; развлечений. Сформулирован перечень видов отдыха, и показана их взаимосвязь с видами туризма, пользуютимися у путешественников наибольшим спросом.
\end{abstract}

Ключевые слова: туристский продукт, туристские услуги, гостиничные услуги, потребитель, мотиваиия, потребности.

\section{MOTIVATION MANAGEMENT OF TOURIST SERVICES CONSUMER}

\begin{abstract}
The motives, that guide travelers when choosing a tourist product, have been considered. The motives have been divided into three types, depending on the degree of interdependence of primary and secondary motives of tourists. The trends, that have a significant impact on the formation of consumer and hotel consumer motivations, have been identified. Based on the analysis of various theoretical concepts of tourist motivation (analytical, hierarchical and complex), it has been proposed to group tourist motivations into the following groups: physical motivations for recreation, cultural and natural-climatic motivations, social motivations, motivations for changes in the type of activity, motivations of status and prestige, and motivations for entertainment. A list of types of recreation has been formulated, and their interrelation with the types of tourism, that travelers enjoy the most demand has been shown.
\end{abstract}

Keywords: tourist product, tourist services, hotel services, consumer, motivation, needs.

В настоящее время при формировании туристского продукта огромную роль играют не услуги материального характера (звездность отеля, комфортабельность транспорта и прочее), а эмоциональная, духовная и культурная составляющие, что связано с насыщением общества материальными продуктами (у $20 \%$ населения мира потребление материальных продуктов достигло точки насыщения и не приносит полного удовлетворения). Д. Огилви пишет о современном потребителе следующее: «нынешние потребители не спрашивают себя, что я хочу иметь того, чего уже не имею»; вместо этого они спрашивают: «что я хочу испытать, чего я еще не испытывал?» [4, с. 126]. Аналогично другой специалист (3. Бауман) утверждает: «Желание приобретать, собирать материальные богатства вытесняется желанием новых впечатлений. Потребитель становится «собирателем» новых ощущений» [1, с. 267]. Таким образом, в современных условиях при формировании туристского продукта туроператорам необходимо наибольшее внимание уделять созданию условий для реализации духовных, культурных и эмоциональных потребностей, ощущений и переживаний путешественника.

В основе любого путешествия с целью туризма лежит мотивация потребителя, на основе которой он принимает решение о выборе туристского продукта, а также туристской дестинации. Мотивация путешественника во многом зависит от его возраста, дохода, взглядов, интересов, физиологических и психологических особенностей, семейного положения, ценностей, склонностей, образования и т. д.

(с) Жукова М.А., 2019. Статья доступна по лицензии Creative Commons «Attribution» («Атрибуция») 4.0. всемирная (http://creativecommons.org/licenses/by/4.0/).

The Author(s), 2018. This is an open access article under the CC BY 4.0 license (http://creativecommons.org/licenses/by/4.0/). 
Изучение мотивов современного потребителя туристского продукта способствует созданию адресных туристских и гостиничных услуг, пользующихся спросом у потенциального покупателя и соответствующего его ожиданиям. В большинстве случаев турист принимает решение о необходимости совершения путешествия на основе целого комплекса мотивов. Поэтому вопрос выявления побудительных мотивов и управление ими имеет первостепенное значение при развитии туризма в том или ином регионе страны, а также способствует популяризации страны в качестве модного туристского направления. При этом важно, с одной стороны, учитывать существующие и перспективные мотивы потребителя при принятии решении о путешествии, с другой заниматься формированием искусственных мотиваций туристов, разрабатывать и активно продвигать модные тренды путешествий в обществе, развивать туристскую и гостиничную инфраструктуры.

Все мотивы, которыми руководствуется потребитель при выборе туристского продукта, специалисты делят на основные (первичные) и дополнительные (вторичные) [3; 7]. Соотношение первичных и вторичных мотивов в значительный степени определяет выбор потребителем того или иного туристского продукта.

1. Основной, преобладающий мотив, все остальные - вторичные. Например, лечение на курорте с термальными источниками. Основная цель - оздоровление организма на основе термальных вод. Среди таких курортов можно выделить: Баден-Баден (Германия), Виши (Франция), Карловы-Вары (Чехия), Висбаден (Германия), Хевиз (Венгрия) и ряд других. Все остальные мотивы (развлекательный, культурный, гастрономический и прочие) вторичны.

2. Основной мотив плюс ряд вторичных, которые могут спонтанно возникнуть при выборе туристского продукта или уже в ходе путешествия. В большинстве случаев это характерно для поездок в такие страны, как: Франция, Италия, Германия, Великобритания, обслуживающие 1/3 мировых туристских прибытий. Выбор экскурсионной программы и развлечений в этих странах настолько широк, что в большинстве случаев он определяется предпочтениями и интересами самих туристов.

3. Основной мотив и перечень четко установленных потребителем вторичных мотивов. Например, пляжный отдых плюс занятия водными видами спорта, экскурсионно-познавательная программа и шопинг. Например, такой вид отдыха с успехом может быть реализован в Испании, Франции и прочих странах.

Целесообразно отметить, что в последнее время сложился ряд тенденций, оказывающих значительное влияние на формирование мотиваций потребителей туристских и гостиничных услуг [6; 9]. Среди таких тенденций можно выделить следующие:

- увеличение количества короткосрочных поездок (от 2 до 7 дней);

- отказ от длительного перелета и смены часовых поясов;

- увеличение интереса потребителей к специализированным видам туризма (сельский, религиозный, экологический, событийный, образовательный и прочие);

- рост влияния общественного мнения друзей и коллег на выбор маршрута путешествия и средства размещения (формирование модных трендов в путешествиях, мест, в которых надо побывать, чтобы соответствовать своему кругу общения);

- увеличение объема самостоятельных путешествий туристов (без помощи туроператоров);

- рост использования в путешествиях различных инновационных (цифровых) технологий, позволяющих упростить знакомство туриста с новым местом пребывания (разнообразные интернет-ресурсы и инновации в средствах размещения);

- формирование устойчивой моды на путешествия и активный образ жизни у населения планеты (многие модные дома в мире предлагают разнообразную одежду для путешествий).

В этих условиях туроператоры должны разрабатывать туристские продукты на основе сочетания различных мотивационных исходов, позволяющих потребителю осуществить выбор того или иного продукта с учетом индивидуальных запросов, требований и предпочтений.

С целью разработки туристского продукта, соответствующего мотивации современного путешественника, целесообразно проанализировать различные существующие в настоящее время концепции туристской мотивации.

Обратимся к аналитическим (описательным) концепциям, которые представляют собой перечень мотивов, которыми руководствуется потребитель при планировании путешествия. Наиболее известные ученые, которые работали и дополняли данные перечни мотивов - Р. Крэнделл (Crandall) и П. Г. Кабанов. Данные исследования были основаны на опросе большого количества респондентов, которые в числе 
наиболее значимых мотивов указали: возможность свободного времяпровождения (3,39 по шкале Ликкерта), семейный отдых $(3,30)$, расслабление $(3,20)$, отсутствие повседневных обязанностей $(3,12)[2]$. Из выделенного списка мотивов следует, что между ними сложно провести разграничение, что позволяет утверждать о сложности выделения мотивов при дальнейшей детализации их перечня.

Рассмотрим иерархические концепции. В основе данного вида мотиваций лежит «пирамида потребностей» А. Маслоу (Maslow), по мнению которого у человека возникает потребность в путешествиях лишь только после удовлетворения потребностей первых двух базовых уровней. В то же время необходимо заметить, что при выборе того или иного туристского/гостиничного продукта потребитель руководствуется необходимостью удовлетворения потребностей всех пяти уровней.

1. Во время отдыха человек восстанавливает физические и психологические силы, поэтому это можно отнести к физиологическим потребностям (первый уровень).

2. Во многом выбор направления поездки туристов определяется потребностями самосохранения (во многих странах власти не рекомендуют туристам посещать страны, в которых имеются военные конфликты, эпидемии или природные катаклизмы) (второй уровень).

3. Путешествия дают возможность людям знакомиться с новой культурой, познавать особенности жизни людей в других странах, общаться, обмениваться мнениями, получать новые впечатления, эмоции, знания - это удовлетворение социальных потребностей (третий уровень).

4. Туризм позволяет реализовать потребность в уважении (четвертый уровень). Во время отдыха многие путешественники стремятся произвести впечатление на окружающих их людей. Опрос туристов показывает, что многие туристы стараются: выглядеть привлекательно во время отпуска (48\%) и иметь с собой одежду, в которой можно сделать яркие фотографии для социальных сетей (43\%). Более того, каждый пятый путешественник (19\%) настолько заботится о своем внешнем виде во время поездки, что готов сэкономить на экскурсиях и других способах проведения досуга, потратив средства на новые вещи [8].

Люди хотят побывать там, где еще не были, но где уже побывали их знакомые или соседи. Новые места - новая информация. Каждый континент, каждая отдельная страна - развивающаяся в течение многих тысяч лет территория и люди, обладающие интересной историей, уникальными традициями и культурой. Познакомившись с другой культурой, человек становится более разносторонним и интересным собеседником в глазах окружающих.

5. Потребность в самовыражении (верхних пятый уровень пирамиды) находит выражение у туриста в первую очередь в его одежде. При выборе гардероба для отпуска путешественники черпают вдохновение у друзей (69\%), членов семьи (60\%), в телевизионных передачах (44\%) и у законодателей моды $(37 \%)$. При этом на стиль во время поездки также влияет множество факторов: разнообразие одежды всевозможных стилей в местных магазинах (53\% опрошенных), местная культура (47\% опрошенных), цвета (40\% опрошенных), стиль одежды местных жителей (43\% опрошенных), пейзажи (32\%), стиль одежды совместно путешествующих туристов (25\%) [8].

На основе классификации А. Маслоу ученые стали разрабатывать аналогичные группировки мотиваций, адаптированные под туристскую и гостиничную индустрию. Например, в классификации Ф. Пирса (Реагсе) выделены такие мотивации, как: «расслабление», «возбуждение», «общение», «уважение» и «саморазвитие» [3]. Интересную теорию мотивации туристов при выборе туристского продукта разработал Д. Шварц, который все типы мотивов разделил на две группы: рациональные и эмоциональные [3]. К рациональным мотивам он отнес:

1) экономия, которая предполагает экономию всех видов ресурсов при выборе туристского продукта (финансов, времени, физических и моральных сил при условии достижения требуемого уровня комфорта). Многие туристы при выборе тура учитывает стоимость путешествия. С этой целью туроператоры активно продвигают разнообразные пакетные туры, стоимость которых ориентирована на туристов со средним доходом;

2) минимизация рисков, стабильность, сохранность жизни, здоровья, имущества, финансовых средств;

3) комфортабельность при достижении места назначения (например, перелета, размещения в гостинице, совершении экскурсионных поездок). Неслучайно наибольшей популярностью у туристов пользуются экскурсии, длительность которых не превышает два часа езды от места его временного проживания. Желание обеспечить комфортный отдых отражается даже в одежде многих путешественников - $60 \%$ опрошенных респондентов предпочитают во время отдыха комфортную одежду; 
4) соответствие качества услуг цене. Важно, чтобы качество туристских и гостиничных услуг соответствовало также и ожиданиям туриста, поэтому огромным преимуществом пользуются у туристов продукты сетевых операторов. Например, международные гостиничные сети имеют разнообразные бренды, рассчитанные на определенный потребительский сегмент. Качество услуг каждого бренда строго контролируется головной компанией. Компания «Marriott International» разделила все 30 принадлежащих ей брендов на две группы - «классические» (classic) и «оригинальные» (distinctive). Например, в категории classic luxury были выделены отели: The Ritz-Carlton, The St. Regis и JW Marriott, а в категории distinctive luxury The RitzCarlton Reserve, The Luxury Collection, Bvlgari, W Hotels и EDITION (по сути это дизайн-бренды). Сделано это было компанией на основе пожеланий гостей для определения восприятия брендов;

5) важным мотивом приобретения туристского продукта является репутация производителей услуг, входящих в турпакет (туристическая компания, авиаперевозчик, средство размещения и прочие поставщики туруслуг), а также имидж места пребывания туриста. Наличие положительных отзывов о курорте, средстве размещения, турфирме являются одним из основных критериев для потребителя при принятии решения о путешествии. В настоящее время все поставщики услуг активно работают над созданием и ведением базы позитивных отзывов клиентов в социальных сетях, на собственных сайтах, а также на сайтах систем онлайн-бронирования.

Д. Шварц считает, что эмоциональные мотивы не менее важны при выборе туристских продуктов. К ним относят следующие.

1. Успех, уважение, признание. Каждый человек хочет, чтобы его ценили и уважали, хочет чувствовать себя значимым в обществе, желает иметь определенный статус.

2. Овладение знаниями. Для потребителей туристского продукта, мотивированных таким образом, необходимо предложение, которое им позволит во время путешествия сделать открытия, получить новые опыт и знания. Выявление потребителей с такой мотивацией очень важно для организаций гостиничноготуристского комплекса. Важную роль в этом могут оказать современные цифровые технологии. В настоящее время на интернет-сайтах многих международных компаний работают чат-боты, которые готовы круглосуточно помогать клиентам в поиске нужной и полезной информации. Специалисты Business Insider считают, что $80 \%$ организаций в 2020 г. будут использовать чат-боты [5]. Такие технологии не просто выполняют задачу на основе заданных правил и алгоритмов, но и накапливают информацию, усваивают логику человека. В результате использования чат-ботов можно обрабатывать огромные объемы данных, искать скрытые закономерности. Также их активное применение создаст настоящий прорыв в обслуживании клиентов, которым можно будет предложить по-настоящему персонализированный сервис.

3. На российском туристическом рынке тоже начинают использовать цифровые технологии. Например, агентство делового туризма «Аэроклуб» успешно внедрило искусственный интеллект в процесс обработки заказов клиентов. На этапе тестирования система смогла корректно распознать почти $65 \%$ заявок на бронирования, которые поступили по электронной почте. Специалисты компании «Аэроклуб» отмечают, что искусственный интеллект на основании данных из письма в более $50 \%$ случаев смог предложить такие условия перелета клиентам, которые бы предложил опытный специалист. В ближайшие два года система будет работать только на бронирование авиабилетов по самому простому варианту point-to-point перелетов. За это время искусственный интеллект сможет накопить данные, научиться выявлять закономерности, что значительно повысит качество предлагаемых вариантов бронирования авиаперелетов. В компании планируют, что к 2020 г. система будет подбирать варианты по всем типам услуг, которые предлагает «Аэроклуб». Также в компании есть планы использовать искусственный интеллект для обработки входящих звонков.

4. Следование модным тенденциям. Среди потенциальных потребителей всегда есть люди, которые при выборе путешествия руководствуются именно этим мотивом. Мода на направления отдыха со временем постоянно меняется. Если в конце 1990-х гг. и начале 2000-х гг. было модно ездить отдыхать в Европу, то сейчас растет популярность отдыха в Юго-Восточной Азии (мода на экзотические страны).

5. Репутация и статус. Например, если деловому путешественнику предстоят серьезные переговоры, результатом которых может стать многомиллионная прибыль, то для размещения в большинстве случаев он выбирает гостиницу пять звезд или класса luxury, что подчеркивает репутацию и статус компании, которую он представляет. При выборе отдыха туристы, имеющие доход выше среднего, обычно ориентируются на курорты и средства размещения, соответствующие их уровню дохода и статусу. 
Выбор потребителем туристского продукта во многом зависит и определяется эмоциональными мотивами. В туристской индустрии часто бывают случаи, когда эмоциональные мотивы человека превалируют над рациональными.

Таким образом, если в аналитических концепциях сформулирован перечень мотивов, которыми руководствуется турист, то иерархические концепции основы на выделении основных видов потребностей путешественников. Однако ученые не остановились на достигнутом, и появился следующий вид концепций мотивации туристов - комплексные.

Авторы этих теорий оперируют двумя состояниями человека: возбуждение и расслабление. Теории направлены на нахождение уровня оптимального «равновесного» состояния человека. Теории утверждают, что чем больше у человека уровень возбужденности (стрессов, напряженной работы) до поездки, тем более расслабленный отдых ему целесообразен. Такая концепция, казалось бы, отвечает на поставленный вопрос. Однако у этих теорий есть один недостаток, который заключается в том, что один и тот же человек в зависимости от ситуации может чередовать активные и пассивные формы отдыха. Автором одной из самых известных комплексных теорий является М. Дж. Аптер (Apter) [2].

Таким образом, проанализировав основные группы теорий мотивации туристов, мотивы туристов целесообразно объединить в следующие группы:

1) мотивации, в основе которых лежит отдых (активный или пассивный): занятия спортом, оздоровление на пляжах, тренировки, связанные с укреплением здоровья и т. п. Все эти мотивации имеют следующую цель: снизить усталость, улучшить самочувствие, укрепить физическую форму человека;

2) культурные и природно-климатические мотивации нацелены на познание мира, другой страны, ее культуры и природы, истории, фольклора, местной кухни, местных обычаев, языка, архитектуры;

3) социальные мотивации предполагают удовлетворение потребности туриста в общении и знакомстве с новыми людьми, расширения круга общения;

4) мотивация изменения вида деятельности предполагает выход человека из привычной среды (повседневных занятий), при котором у человека возникает потребность в выборе отдыха диаметрально противоположном работе;

5) мотивации статуса и престижа связаны с «я» человека и его персональным развитием;

6) мотивация развлечений направлена на удовлетворение потребности человека в ярком, веселом времяпрепровождении.

На основании выделенных групп мотиваций туристов сформулирован перечень видов отдыха, которые предпочитает большая масса потребителей:

1) отдых, носящий неторопливый восстановительный характер;

2) активный отдых (возможно с спортивными занятиями);

3) познавательно-культурный отдых;

4) зрелищный, развлекательный, легкий отдых;

5) лечебно-рекреационный отдых.

Отметим, что несмотря на наличие значительного количества теорий мотивации о поведении человека, все они трактуют потребности и мотивы туриста по-разному, что объясняется индивидуальностью каждого человека, его психологией, поведением, склонностями и интересами. Сложность определения мотивов поведения путешественников вызвана также тем, что современные условия развития экономики и общества ведут к появлению у различных людей совершенно противоположных потребностей (например, обособленность человека и жизнь в группе; стабильность в жизни и поиск нового; расслабленный образ жизни и деятельный (созидательный); пассивное потребление и активное проведение свободного времени; «пускание корней» и отсутствие «корней»; проведение отпуска по разработанной туроператором программе и самостоятельное формирование маршрута.

Рассмотренные выше мотивации туристов целесообразно отнести к виду - естественные мотивации, которыми могут руководствоваться потребители при выборе туристского продукта. Естественные мотивации туриста предполагают, что тот или иной туристский продукт, предлагаемый на рынке, удовлетворяет его основные мотивы и потребности.

В то же время для развития туризма в ряде российских регионов наличие только естественных мотиваций у потребителя недостаточно для обеспечения оптимального туристопотока в дестинации. С этой 
целью имеет смысл говорить о дополнительных направлениях работы государственных и региональных организаций, направленных на создание новых туристских и гостиничных комплексов, событий и мероприятий, культурно-исторических объектов, природных территорий, представляющих интерес для туристов. Развитие таких новых объектов требует на начальной стадии формирования у потребителя искусственно созданных мотиваций путем активной рекламной деятельности и продвижения, что будет способствовать увеличению туристопотока в регионе. Использование искусственно созданных мотиваций для потребителя туристского продукта предполагает, что регион, развивающий туризм, ориентируется на определенный вид мотиваций туриста и на соответствующие данным мотивациям виды туризма (табл. 1).

Таблица 1

Взаимосвязь типов отдыха туристов с видами туризма

\begin{tabular}{|c|c|c|c|}
\hline Тип отдыха & Основной вид туризма & $\begin{array}{c}\text { Дополнительный вид туризма } \\
\text { к основному }\end{array}$ & Вероятный вид туризма \\
\hline $\begin{array}{l}\text { Отдых, носящий неторо- } \\
\text { пливый восстановитель- } \\
\text { ный характер }\end{array}$ & $\begin{array}{l}\text { Пляжный } \\
\text { Рекреационный }\end{array}$ & $\begin{array}{l}\text { Культурно-познавательный } \\
\text { Лечебно-оздоровительный } \\
\text { Развлекательный } \\
\text { Событийный } \\
\text { Экологический }\end{array}$ & $\begin{array}{l}\text { Спортивный } \\
\text { Приключенческий }\end{array}$ \\
\hline Активный отдых & $\begin{array}{l}\text { Спортивный } \\
\text { Приключенческий } \\
\text { Экологический } \\
\text { Сельский }\end{array}$ & $\begin{array}{l}\text { Пляжный } \\
\text { Рекреационный } \\
\text { Культурно-познавательный } \\
\text { Развлекательный }\end{array}$ & Лечебно-оздоровительный \\
\hline $\begin{array}{l}\text { Культурно-познаватель- } \\
\text { ный отдых }\end{array}$ & $\begin{array}{l}\text { Культурно-познавательный } \\
\text { Событийный } \\
\text { Сельский } \\
\text { Образовательный }\end{array}$ & $\begin{array}{l}\text { Рекреационный } \\
\text { Приключенческий } \\
\text { Развлекательный }\end{array}$ & $\begin{array}{l}\text { Пляжный } \\
\text { Спортивный } \\
\text { Лечебно-оздоровительный }\end{array}$ \\
\hline $\begin{array}{l}\text { Зрелищный, развлекатель- } \\
\text { ный, легкий отдых }\end{array}$ & $\begin{array}{l}\text { Развлекательный } \\
\text { Событийный }\end{array}$ & $\begin{array}{l}\text { Пляжный } \\
\text { Культурно-познавательный } \\
\text { Спортивный } \\
\text { Приключенческий }\end{array}$ & Рекреационный \\
\hline $\begin{array}{l}\text { Лечебно-рекреационный } \\
\text { отдых }\end{array}$ & Лечебно-оздоровительный & $\begin{array}{l}\text { Пляжный } \\
\text { Рекреационный } \\
\text { Экологический }\end{array}$ & $\begin{array}{l}\text { Культурно-познавательный } \\
\text { Событийный } \\
\text { Развлекательный }\end{array}$ \\
\hline
\end{tabular}

Составлено автором по материалам исследования

Таким образом, можно сказать, что бурное развитие туриндустрии в настоящее время во многом связано с трансформацией общественного сознания. Сегодня у современного человека в структуре ценностей качественный отдых, удовлетворяющие его индивидуальные потребности, занимает далеко не последнее место. При организации туристической поездки потребитель хочет иметь с одной стороны, разнообразный отдых, с другой - путешествие должно быть организовано таким образом, чтобы оно соответствовало его интересам, стремлениям, ожиданиям. Эти требования современного потребителя туристских услуг должны учитываться при развитии туристской, гостиничной и смежной с туризмом инфраструктуры в российских регионах для развития их туристской привлекательности.

\section{Библиографический список}

1. Бауман, 3. Индивидуализированное общество / Пер. с англ. Под ред. В. Л. Иноземцева. - М.: Логос, 2005. -390 с.

2. Васильева, К. Социально-психологические аспекты управления поведением потребителя // Вестник современных исследований. - 2018. - № 4-1 (19). - С. 113-114. 
3. Илькевич, С. В. Тенденции развития концепции сервисного менеджмента: анализ зарубежных исследований // Сервис в России и за рубежом. - 2015. - Т. 9. - № 2 (58). - С. 176-193.

4. Огилви, Д. Огилви о рекламе. - М.: Манн, Иванов и Фербер, 2017. - 304 с.

5. Патахова, М. А. Анализ и оценка поведения потребителей под влиянием российского и регионального рынка туристических услуг / М. А. Патахова, К. Д. Дахдуева // Экономика и предпринимательство. - 2017. - № 9-4 (86). - С. $1060-1063$.

6. Солнцева, О. Г. Основные факторы привлечения и удержания клиентов в индустрии гостеприимства. / Материалы V Всероссийской научной конференции «Львовские чтения». - Москва: ГУУ - ЦЭМИ РАН, 2017. - С. 159-163.

7. Чудновский, А. Д. Управление потребительскими предпочтениями в сфере отечественного туризма и гостеприимства, и основные направления реализации туристского продукта: учебное пособие / А. Д. Чудновский, М. А. Жукова. - М.: Федеральное агентство по туризму, 2014. - 304 с.

8. Мода и путешествия: как наша одежда влияет на впечатления от поездки [Электронный ресурс]. - Режим доступа: https://hotelier.pro/news/item/3476-moda-i-puteshestviya-kak-nasha-odezhda-vliyaet-na-vpechatleniya-ot-poezdki (дата обращения: 07.01.2019).

9. Bunakov, O. A. The use of the «soft power» concept in the modern Russian tourism industry / O. A. Bunakov, N. A. Zaitseva, A. A. Larionova, V. A. Zhukov, M. A. Morozova, N. V. Dmitrieva // ESPACIOS. - 2018. - V. 39 (I. 22 ). - P. 2.

\section{References}

1. Bauman Z. Individualizirovannoe obshchestvo [Individualized society]. M.: Logos, 2005. 390 p.

2. Vasil'eva K. Sotsial'no-psikhologicheskie aspekty upravleniya povedeniem potrebitelya [Socio-psychological aspects of consumer behavior management]. Vestnik sovremennykh issledovanii, 2018, I. 4.1 (19), pp. 113-114.

3. Il'kevich S. V. Tendentsii razvitiya kontseptsii servisnogo menedzhmenta: analiz zarubezhnykh issledovanii [Trends in the development of the concept of service management: an analysis offoreign studies]. Servis v Rossii i za rubezhom [Service in Russia and abroad], 2015, T. 9, I. 2 (58), pp. 176-193.

4. Ogilvi D. Ogilvi o reklame [Ogilvy about advertising]. M.: Mann, Ivanov i Ferber, 2017, p. 304.

5. Patakhova M. A. Analiz i otsenka povedeniya potrebitelei pod vliyaniem rossiiskogo i regional'nogo rynka turisticheskikh uslug [Analysis and evaluation of consumer behavior under the influence of the Russian and regional tourism services market] Ekonomika i predprinimatel'stvo, 2017, I. 9-4 (86), pp. 1 060-1 063.

6. Solntseva O. G. Osnovnye faktory privlecheniya i uderzhaniya klientov v industrii gostepriimstva [The main factors attracting and retaining customers in the hospitality industry]. Materialy V Vserossiiskoi nauchnoi konferentsii «L'vovskie chteniya» [Proceedings of the V All-Russian Scientific Conference «L'vovskie Readings»]. M.: GUU-TSEMI RAN, 2017, pp. 159-163.

7. Chudnovskii A. D., Zhukova M. A. Upravlenie potrebitel'skimi predpochteniyami v sfere otechestvennogo turizma i gostepriimstva i osnovnye napravleniya realizatsii turistskogo produkta [Management of consumer preferences in the field of domestic tourism and hospitality, and the main directions of implementation of the tourist product]. M .: Federal Agency for Tourism, 2014 . p. 304.

8. Moda i puteshestviya: kak nasha odezhda vliyaet na vpechatleniya ot poezdki [Fashion and travel: how our clothes affect the impressions of the trip]. Available at: https://hotelier.pro/news/item/3476-moda-i-puteshestviya-kak-nasha-odezhda-vliyaet-na-vpechatleniya-ot-poezdki (accessed 07.01.2019).

9. Bunakov O. A., Zaitseva N. A., Larionova A. A., Zhukov V. A., Morozova M. A., Dmitrieva N. V. The use of the «soft power» concept in the modern Russian tourism industry. ESPACIOS. 2018,V. 39, I. 22, p. 2. 